DOI: $10.20472 / E F C .2021 .015 .009$

\author{
CLAUDIA VAN DER VORST \\ FACHHOCHSCHULE KUFSTEIN TIROL Bildungs GmbH, Austria
}

\title{
HIGHER EDUCATION TURNAROUND SUPPORTING DIGITAL TRANSFORMATION
}

\begin{abstract}
:
Since years the education system was about to change. Specifically, the focus with this paper is on Germany where the schools and most universities are public. Rules are related to the past, skills like deep functional knowledge, topics memorised in detail and repetitive methods have been on top of the educational syllabus. After the trends of globalisation, the introduction of the term 'Industry 4.0' provocative production and automation. All of a sudden industry has been challenged globally with new skills and requirements asking the education system to support with a more profound skills of graduates being 'digital natives' per definition. To change a system takes time, infrastructure and advanced training. (cf. Catalano, 2019, p.25f)

What if there is no time for this transformation? In the beginning of 2020 the Pandemic Covid-19 hit the world and all schools and universities been shut for people's safety. It started as a break but after a while people figured even arguing about the quality of online education versus in-person learning did not help. Remote education was the only way to get in contact with students and pure self-learning needed to be enriched by more motivating methods. All of a sudden, all parties had new roles. Some really felt overstrained and had very little experience. To start a mature semester in autumn, and moving from mainly remotely to an at least hybrid format for the rest of the year, teachers extended their knowledge of digital tools and exchanged it. Over the year faculty increased comfort and some approaches seems to remain even if all teaching could be in presence. (cf. Boivin et al., 2021, p.27ff)

Not only the education system was challenged during the pandemic in 2020/21, the entire world and business world had to adapt. Comparing only with the new business requirements of production companies, shows that a lot of the skills the students learned in remote sessions will remain in business situations (e.g. video conferencing, online presentations, self-motivated learning). In addition, the speed of change increased and with the penetration of digital transformation everywhere, now is the time to change the main structure of curriculars adding more profound skill sets in human interaction, practical adaptation of skills versus just having knowledge building new characters for life-long learning. (cf. Meilleur, 2018)
\end{abstract}

The questions are remaining; 'What is the role of online-education past the pandemic?' 'What could be a new setting in education taking the learnings from the pandemic Covid-19 to map new requirements from the industry and for future jobs?' The paper will not be able to provide one clear answer but will provide a good start of research.

\section{Keywords:}

Life-long Learning, Higher Education, Industry 4.0, Education 4.0, Digital Change, Digitalization, Learning Methods, Project Based Learning, Self-paced Learning, Past-Pandemic Teaching

JEL Classification: A20, D20, D83 


\section{Introduction and Relevance}

Learning and teaching in schools been based on very traditional methods specifically focusing on Germany, for this paper, where schools are mainly public. Even at Universities, the possibilities and structures are very traditional. Information have been selected and splitt in meaningful and teachable bits and pieces which can be tested easily. This approach for teaching developed and professionalized the past 50 years can be automated as well. It is just pure information and data even less knowledge as a basis. It was clear that education and teaching methods had to change. This century started to be very challenging not just for all business but also for all sectors in education. Information is available on a much more intensive range than ever on a permanent accessible basis. The challenge for students is nowadays to select quality of information, structuring it and selecting the most important ones. They have to gain knowledge and develop skills for areas which are not even been generated. The education landscape has been seen under main construction forcing the different areas to change and develop and educate a new generation of teachers and professors. It is a longer process because there is not the one toolset to change. Long traditions and knowledge are losing its value very quickly and there is no immediate replacement. Knowledge and people can not be differentiated in generalists and specialists, they have to gain additional versatile competences and completely new disciplines. (cf. Fadel et al., 2017, p.2f)

Ever since in 2011 the term Industry 4.0 was introduced, companies try to define and understand what it mainly means for their business. It is unclear how it will develop but Industry 4.0 or digitalisation impacts and changes happens more rapidly than ever. The definition covers a wide range in the production industry, not just automation of systems but building cyber physical systems, connecting a fast-moving global world with new technologies and changing business models. For the first time, knowledge is renewed faster than generations. We consume, in a single day the amount of information that people in the middle ages had consumed during a lifetime. (cf. Meilleu, 2018). The pandemic in 2020/21 caused disruption of all sectors in all businesses and changed the requirements of industries in addition. So, the ongoing shift between human, machines, automation and algorithms might displace a lot of jobs in the near future. All companies which neglected the change before, are now forced to act according to any kind of digital transformation.

After the pandemic all areas are in the process of reinvention, a lot of still mature areas are disrupted and higher education had been forced to change more than anyone else. This is an opportunity given the requirement for digitalization of education been on for a long term. (cf. Llopis, 2020)

The main aim of this paper is to investigate what is required from institutes of higher education to enable current students to prepare them for future jobs and motivate them and set a foundation for lifelong learning. Considering their specific digital capabilities with the boost of the pandemic increasing the use of digital infrastructure. 
The overall key research questions for this paper are:

'What is the role of online-education past the pandemic?'

'What could be a new setting in education taking the learnings from the pandemic Covid19 to map new requirements from the industry and for future jobs?'

Supporting these questions four hypotheses have been defined which will be evaluated in more detail in the main chapters basically with literature research and questionnaires as a qualitative research method.

Limitations: The detailed research is limited geographically to the southern part of Germany, Bavaria and Tirol in Austria given the education is similar cross these countries. For concrete analysis interviews and the experience teaching students of technical faculties of the university of applied science in Kufstein was taken as a basis as well as questionnaires which has been executed at the beginning and past the third wave of the pandemic cross pupils and students. Due to the actuality of the topic the research considers a timeframe of the last 10 years (Year 2010 plus) focusing on the pandemic specifics in the year 2020/2021.

\section{Definitions}

The key terms are defined at high level for the purpose of this paper. Given the actually of the topic and many uncertainties the terms are clearly stated and defined.

Pandemic COVID-19; the Coronavirus disease 2019 also known as Coronavirus or COVID-19 is a disease which is caused by the coronavirus (SARS-CoV-2). It is an infection caused by the virus and transported via people. By end of 2019 it was spread from China - all over the world. Causing severe shot-downs of the entire economies for the first quarter 2020 followed by the second and third wave until May 2021 so far. In this content schools \& universities e.g. in Germany \& Austria have been shut from mid-March 2020 until June 2020 and from November 2020 until May 2021.

Industry 4.0 as well as Digitalization / digital transformation, are terms which have the foundation on the Hanover Fair in 2011. Even 10 years later there is no common definition. Basically, the term transferred the past years to digitalization or a digital transformation. For the matter of this paper the definition of Schuh will be taken as a basis. It was recognized that a huge growth is offered by digitalization, interconnectedness and new manufacturing technologies. These phenomena together are driving new business models, sustainable and efficient use of limited resources and the cost-effective production of highly customizable products. These developments are referred as the term "Industry 4.0". (cf. Schuh et al., 2017, p.7)

Education 4.0 is similarly a term used with not a common definition. It is having been created in the context of Industry 4.0 but greatly used by the World Economic Forum Platform for better education. It should provide quality education taking the opportunity after COVID-19 crisis to 
deliver new skills, new mechanisms for learning and training ecosystem using new digital tools and digital / social-emotional skills. (cf. no author WEF, 2021).

Some more terms in the context of Education 4.0:

E-Learning; meaning electronic learning for all formats of learning using electronic devices supported by technical and digital tools. Focus is on self-determined learning including AR /VR, Videos and interactive exercises.

Online-Training; meaning a live online seminar which is simultaneous for all parties. E.g. MS Teams session. Interaction can be possible but doesn't have to be.

Hybid-Training; meaning a combination of in-classroom teaching with online trainings and selfstudy E-Learning parts. A high level of didactical education and deep skills in all teaching methods are required to perform a high-quality hybrid training.

Blended Learning, meaning a combination of in-classroom trainings with digital and self-study components. (cf. Berg et al., 2020, p.4).

Digital Natives, firstly introduced by Prensky in 2001. Meaning the use of technology is natural always connected to a device like phone, laptop, tablet or smartwatch. But digital connected does not mean digital educated. The learning approaches are completely different given the availability of endless date anytime. (cf. Catalano, 2019, P. 25f) 


\section{Requirements from the Industry}

It has to be differentiated between the needs of the industry in future jobs and related skills and requirements to run them for cross disciplines. Somehow, they are connected and challenged by the same forces. At the World Economic Forum these forces are called twin forces, a very good expression that the world and economy was hit by both. Firstly, the Forth Industrial Revolution and Digitalization and secondly by the pandemic COVID-19. As a result of it and the recession day to day digitalization has leapt forward, with a large-scale shift to remote working and ecommerce, driving a surge in work from home arrangements and a new marketplace for remote work. (cf. Schwab et al. 2020, p.16)

Related to the assumed changes to Industry 4.0 many studies had been executed and headlines published like "how many jobs will be replaced by robot's?". A very mature study of the Oxford University concluded that $47 \%$ of the jobs are at risk meaning expected to be automated relatively easy. (e.g. Frey et al. 2013, p.44) Looking back in history jobs have been changing as well as qualifications but the human workforce still remains highly required. According to Meilleur the crucial skills for 2020 in comparison to 2015 changed to be more creative and emotional intelligence is a key ability to have. The wake up with Industry 4.0 led by digital technologies and transformation is that "human" qualifications become popular again. The major findings have been that:

- Developing creativity will support the change using technological advantages

- While Robots and artificial intelligence (AI) will automate a lot of work processes the human skills to manage people, collaborate and emotional intelligence cannot be replayed

- Finally, workers which are capable of solving complex problems will always be required

The view just on the requirements of the 'first force - Industry 4.0' have been:

Complex problem solving, critical thinking, creativity, people management and coordinating with others just to name the first five main competences (cf. Meilleur, 2018a)

The World Economic Forum published the same trend years before.

\section{Top 10 skills}
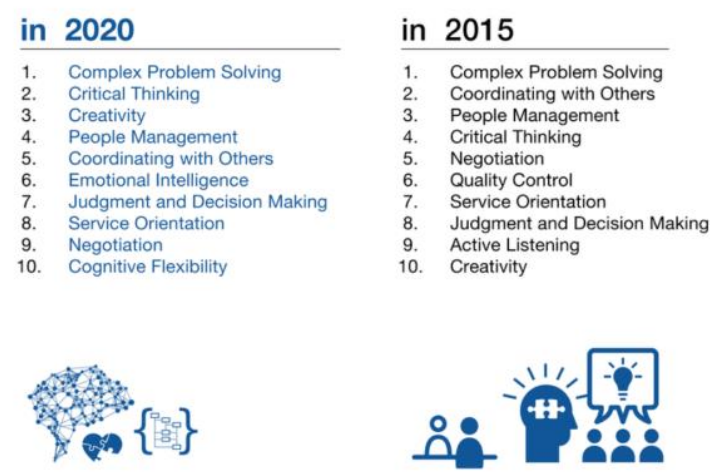

Figure 1: Top 10 skills required according to Industry 4.0 change (cf. Gray, 2016) 
The world economic forum had the focus on the forced changes related to the $4^{\text {th }}$ Industrial Revolution looking at the disruption in industry. The first major changes been in the global media and entertainment industry. The financial services and investment sector were the next one to be transformed. In parallel the diverse production industry tried to create a strategy for the future using all the new methods, technological skills and tools, changing the work significantly along with Artificial Intelligence, 3D printing and mobile internet / devices. (cf. Gray, 2016). Specific skills will have to change in sync with these requirements. Skills which been on top of the list in 2015 will drop or disappear related to the new requirements. The change will require retraining and up-skilling on all levels.

When the second force, the COVID-19 pandemic, hit the world in 2020 it was the biggest global crisis of our time. Nearly every sector of the economy gets disrupted and it remains unclear how some areas will develop \& survive in the future. In production the combination of both forces let people lose their jobs. The accommodation and food services industry impacted most about $47 \%$ lose jobs, followed by wholesale \& retail, transportation, construction and education by expected $15 \%$. Manufacturing and even health care with $14 \%$. While everything is disrupted and things are changing it is as well an opportunity. Habits changed much faster as ever expected and specifically the use of digital devices and remote working did get an enormous boost. The future will need a lot of employees, new skills and skilled workers, but the expectation is that a great part (about $40 \%$ ) of the workforce needs training and reskilling. (cf. n.a., 2020a. WEF, p.17).

Planned business adaptation in response to COVID-19

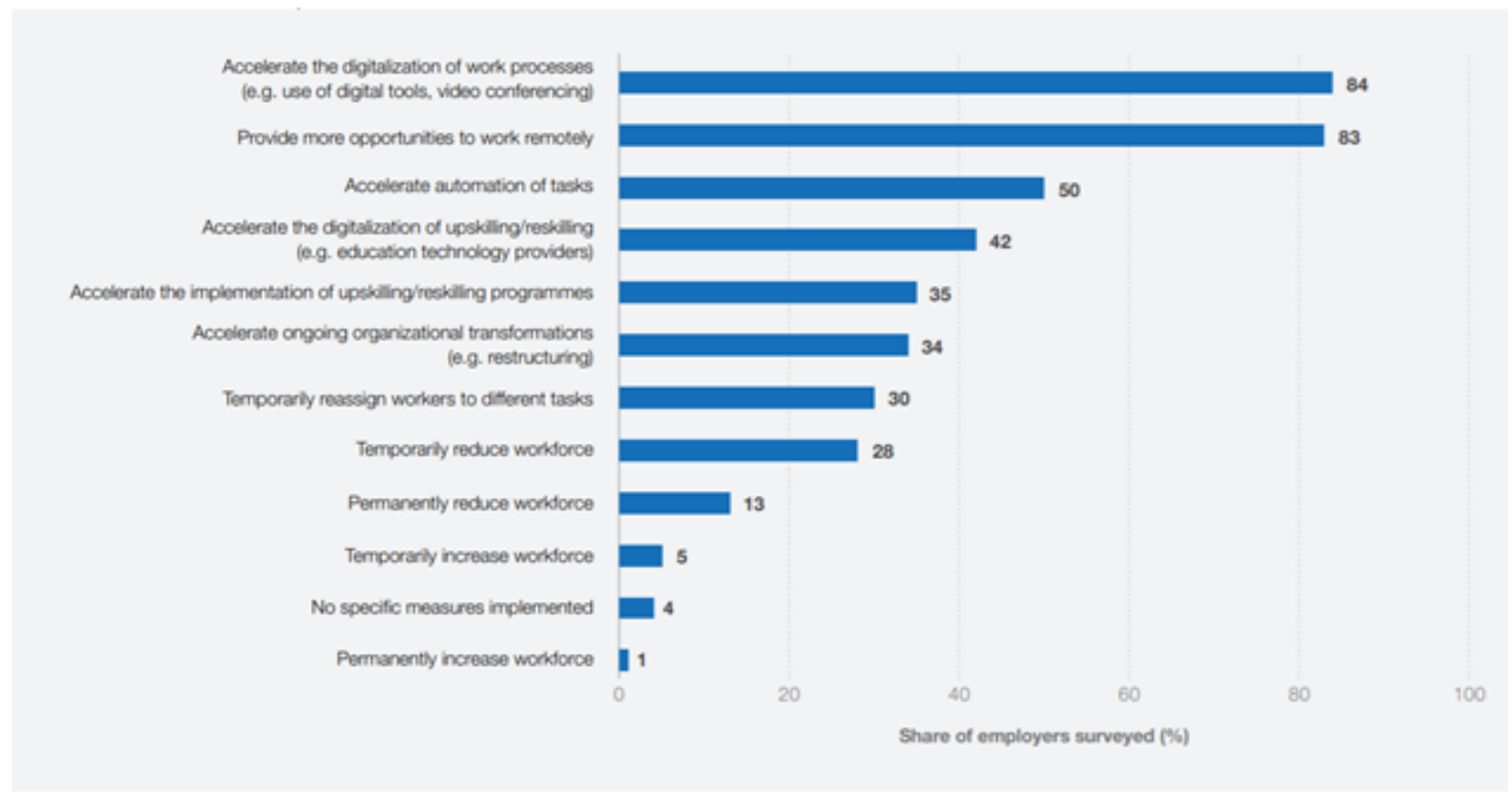

Figure 2: Business adaptation planned, (cf. Schwab et al., 2020, p.14) 
These assumptions and collection of quotes are mainly confirmed in the report of future jobs of the World Economic forum 2021. All the expected business adaptations (see Figure 2) and the key report findings about the industry changes will lead to a change in skills. The key findings match the ongoing trend of digitalization. Technology adaptation is expected to remain rising as well as automation is still accelerating, jobs will be destroyed and new ones created and the value of human capital is recognized more than ever. Most important is to use this window of opportunity to reskill and upskill the workers as well as developing online trainings for new skills. (cf. Schwab et al., 2020, p. 5f)

Taking the two forces into consideration not only the jobs and job requirements are changing the skills. Skill sets required changed more rapidly than ever expected. Given specifically in the teaching area digitalization got an unexpected boost these skills will have to be strengthen the next few years and significantly developed. The importance of skill groups has been evaluated by the companies and it did change in comparison to the pre-COVID prediction. The main increase has now the skill groups around 'critical thinking and analyzing skills', 'problem solving', 'selfmanagement' 'technology use and development' and 'working with people'. (cf. Schwab et al., 2020, p.36)

\begin{tabular}{|c|c|c|c|}
\hline 1 & Analy tical thinking and Innovation & 9 & Reslllence, stress tolerance and flex|bllity \\
\hline 2 & Active learning and learning strategles & 10 & Reasoning, problem-solving and Ideation \\
\hline 3 & Complex problem-solving & 11 & Emotional Intelllgence \\
\hline 4 & Critical thInkIng and analysls & 12 & Troubleshootling and user experlence \\
\hline 5 & Creatlvity, orlginallty and InItlative & 13 & Service orlentation \\
\hline 6 & Leadership and soclal Influence & 14 & Systems analysls and evaluation \\
\hline 7 & Technology use, monltoring and control & \multirow[t]{2}{*}{15} & \multirow[t]{2}{*}{ Persuasion and negotlation } \\
\hline 8 & Technology design and programming & & \\
\hline
\end{tabular}

Figure 3: Top 15 skills for 2025, (cf. Schwab et al., 2020, p.36)

As stated, it will become very important to learn, retrain people and actively involve the people in a life-long learning process. Therefore, it will be a longer path to integrate all employees in this process. With the shutdown of the universities for many months in 2020/21 the Education 4.0 experienced a major boost in comparison to any forecast pre-pandemic.

The economist James Bessen statet: 'learn to learn'. (cf. Meilleur, 2018a). the education system does need this unique chance to flexibly adapt. Learning, training and teaching strategies need to be developed and remain in new education environment for all future jobs. 


\title{
4. The challenges pre- and past pandemic according to digital education
}

„No problem can be solved from the same level of consciousness that created it.“

\author{
-Albert Einstein -
}

Education in the 21th century has been politically and economically discussed in length. Latest the rapidly increasing set of information with the major use of the internet started the discussion of the digitalization of schools and universities. The world, for which the education system was prepared for didn't exist for much longer. The internet was the first global, interactive and social communication media where the entire world had access to. Therefore, the impact was enormous. The changes in all areas of the economy had an impact on all requirements of learning strategies. All of a sudden, the education system got universal and all students been connected. The importance was to remain with a universal point of view having global goals and understand the consequences in the content of a global world.

A new framework had to be developed not to just take the challenges of new functional skills but to relate and learn new digital tools as well as business processes and strategies related to a digital world. Latest with the introduction of Industry 4.0 in 2011 there have been a lot of voices to change the teaching strategy completely and the curricular towards new required skills. (cf. Trilling et al. 2009).

People have to renew their skills on a frequent basis, they cannot rely on their deep functional knowledge - not for a lifetime anyway but sometimes not for a year. What seems unbelievable for more mature people is just normal for the generation of digital natives. It is estimated that the digital skills need to update every three years. (cf. Catalano, 2019).

The four powerful forces are converging and leading us toward new ways of learning for life in the 21st century: Knowledge work, thinking tools, digital lifestyles and learning research. They simultaneously are creating the need for new forms of learning in the 21st century and supplying the tools, environments, and guiding principles required to support learning practices. (cf. Trilling et al. 2009, chapt.2.1).

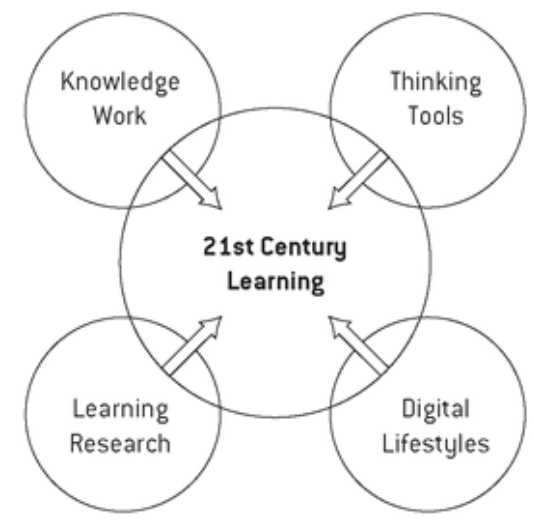

Figure 4: 21st Learning Styles (cf. Trilling et al., 2009) 
The figure 4 show that learning in the $21^{\text {st }}$ century is not about learning deep functional skills, just pure information is not required any more, it is the knowledge, the use of it in combination with critical reflection and thinking as well as realizing the potentials of new technology. Due to the availability of the internet and therefore information everywhere the requirements for future capabilities are being versatile. Changing the above styles even more mature are the four dimensions having information, gaining knowledge and building a character to reflect on a higher level and be able to self-motivate and self-learn. Future requirements for students are to be able to transfer knowledge to new situations. It is the productive use of knowledge and motivation. (cf. Fadel et al, 2017, p. 77).

Teaching is moving from disseminating knowledge to personalized teaching. Teachers are taking new roles and the digitalization of universities are supporting these new requirements. With the revolution of the social Web and information technologies the world is moving faster and the halfvalue period of the information is declining. Outlining the requirements of the Industry for future knowledge shows that the next generation need to be prepared to constantly update and reskill themselves. It is the generation of lifelong learning. The next education system needs to prepare this generation for a level of uncertainty. Therefore, the training and teaching style has to adapt. Sitting long hours in classrooms is not adequate in an age of high technological, flexible environment where basic knowledge is available 24/7. Universities and Education Styles need to be adapted. The benefit of classroom education has to be outlined, being practical case studies, laboratory work, team work or anything but pure theory read of slides. (cf. Meilleur, 2018).

\section{Past pandemic teaching}

Taken on the requirements for future jobs it is important to consider that a huge change in human education has to happen. Decades have shown that human capital is the most valuable asset of a company but there is a major lack of relevant skills for future roles. Even more now after the massive changes of structures and jobs past-pandemic. Companies are prepared to invest in the training of their workforce. Companies expect to train about $70 \%$ of their workforce the next 5 years. Whether it will take just 2 weeks or 6-month training it will be required to pick up the new roles. It is a unique opportunity now in 2021 to restart given company training is set up. (cf. n.a., 2020a. WEF).

Higher education has been challenged more than every other industry during the pandemic to act instantly, remain in business and in parallel develop a new strategy. Even if the immediate impacts of COVID-19 are over the education stream will never be the same as pre-pandemic. Faculty been challenged to take instant action using the digital devices which have been in the drawer for too long. The process of massive reinvention finally started and the students have been part of it. Professors learned to teach in new ways and student learned in new ways. This process can and should not be stopped but need to be professionalized. COVID-19 has changed the trajectory of higher education and this opportunity has to be taken. All students are expecting a continuous use of digital devices as well as more flexible education strategies. (cf. Llopis, 2020). Higher Education and Universities have to reinvent themselves. 
At the beginning of the pandemic in spring 2020 there was a huge consensus that staying at home was the safest decision. Recognizing that this will not be just a short break most institutions took an initiative. Digital teaching devices which have been in trial modus so far became the daily business and teachers became very creative in remote teaching. While official decisions been outstanding the education community of teachers and students worked out some very practical approaches. The well-prepared structure of a classroom curricular disappeared and teachers and students educated themselves using the new devices experimenting new structures.

The summertime where COVID-19 slowed down a bit most institutes and universities took the time to prepare and educate teachers, basically in technical devices, setting up a common infrastructure and changing the content to be teachable outside the pure classroom training. The preparation for the winter semester started and without a crystal ball what might happen in terms of the pandemic, most schools and universities prepared for a hybrid format. From being in classroom pre-pandemic and being just at home remotely during the pandemic the format and methods had to be developed for the past-pandemic phase. Unfortunately, with the third wave the swing went back and force between one or the other but now it is the time to prepare for an almost stable future. (cf. Boivin et al., 2021)

The next step will be to create new teaching and learning environments combining the best of all worlds reviewing it with the learning capabilities of the students and most important change schedules to all the new requirements of skills (see chapter 3 ).

The challenge of this digital era past pandemic is to train all professors and teachers. Digital devices are motivating and closer to the mindset of the younger generation (e.g. digital natives). A wider change in higher education and university systems is needed to prepare for the response to digital technology in education. Students are expecting to replace that the old intellectual tools got replaced by new methods and a digital environment. Developing from a mass-produced university degree to very individual studies in an individual pace and structure. (cf. Catalano, 2019, p.27)

Looking at the requirement for skills to be educated in the future, digital know how will be essential in the future. The teachers and trainers do have to rapidly increase digital knowledge of devices, tools and teaching strategies. They should get ahead or at least not behind their pears in the companies or the pupils at school. Therefore, train the trainers is the next major task in Education 4.0 while doing their day to day jobs. The University of Passau for example opened a studio to do video's and online tutorials and train and help all their trainers how to do so and how to use the technology. (cf. n.a. 2021, Digital Passau).

Summarizing, with the two forces, digitalization and the pandemic education, was majorly disrupted as all the other economical areas as well. Industry is requiring different skills as before more focusing on humanity and critical reflection ensuring the use of digital tools. Teachers and trainers need to be educated to use the tools as well as respond to the new way of hybrid teaching. 


\section{Research Question and Method}

This research was developed based mainly on literature research and qualitative questionnaires with pupils / students. Due to its assumptions and limitations the research remains qualitative. The results of the questionnaire provide a point of view on the research results. All people asked are fulfilling a high set of experience given their years as students in schools and universities. In addition, the experience teaching for over 10 years using a certain structure and evaluating feedbacks have been considered.

The overall key research questions for this paper are:

'What is the role of online-education past the pandemic?'

'What could be a new setting in education taking the learnings from the pandemic Covid19 to map new requirements from the industry and for future jobs?'

Education is an essential topic looking at the future and the remaining debates of politicians and the industry about the lack of skilled workers and engineers for the future. The last decade has been dominated by new developments in many sectors and the certainty of globalization in a cyber physical world. It was a time of individual development with ideas of interaction but not finally connected areas. What seems a wild idea 10 years ago is developed, up and running nowadays. The speed of development is never ending and the pressure on the education system to adapt is high.

The possibility of online education increased with the distribution and accessibility of the internet this century, followed by the development of mobile devices. Nevertheless, the development and acceptance at schools and university was very slow. Some universities focused on distance learning and prepared specific curriculars for it but the combination of online versus classroom education remained rare. With more topics related to digitalization and Al some Professors and Universities volunteered. Specifically, in the US, the development of MOOC's ('massive open online course') driven by e.g. Sebastian Thrun at Stanford University. A lot of students started to use Youtube tutorials in addition to classroom training but more as an additional source not integrated in the daily schedule. Quotes like 'these tools are fun', 'help me to learn things on my own' and 'let me learn at my own pace' been captured in a survey in 2019 where 1618 students been asked. (cf. Duffin, 2020). But in addition, the students mentioned these digital learning tools 'help me to prepare'. 'help me to focus in class' and 'I want to use them more often'. The foundation of digital learning tools been set just before the pandemic hits the world.

$\mathrm{H} 1$ : Students have been prepared to use digital tools before the pandemic

H2. Students prefer to use these eLearning facilities past the pandemic

This Hypotheses will investigate if the current students are okay using digital facilities in general, given Universities are currently following a more traditional approach as well as schools at their primary education. All pupils and students do know a lot of the tools but there were very little possibilities to make themselves familiar with it given the traditional teaching in class. 
Reviewing the requirements form the industry (see chapter 3) students will have to gain skills on learning methods, transferring knowledge in to skills and building a personality of life-long learning for a changing environment. These students are challenged more or differently then any generation before. They are the contemporary witnesses of transformation.

The traditional approach was to split all information in bits and pieces and teach this as knowledge. But this knowledge doesn't last for a life-time any more. Rarely a worker or engineer will have to fulfill the same task for the entire life. Information is replaceable - it is available any time. Usually the education system was developed as an answer to requirements of the industry. Now it needs to be ahead.

Given we all do not know the future requirements in details we do need to enable the current generation with a tool box of methods, information and practical experience for the future. In addition, we do need to split skills in the ones which can or can not be automated. This will give us an even deeper insight what students need to learn in addition to functional knowledge. Reviewing the possibilities there will be new subjects for each student to learn cross and independent from all disciplines. (cf. Fadel, 2012, p.8ff).

H3: Students do need to learn methods and tools in a practical environment e.g. self-paced projects.

The next question is pretty much related to the previous one specifically for the leaners. Which skills are required goes in sync with how to enable students. What do they need to change? The last century on beyond the entire education system been based on learning and replicating information. Therefore, the new skills required are for both the teaching parties and the learning ones.

"If we teach today's students as we taught yesterday's we rob them of tomorrow."

$$
\text { John Dewey }{ }^{1}
$$

H4: New structures for Education have been introduced in the time of the pandemic

By the major disruption of the pandemic teachers need to be trained. Starting with training themselves using digital learning environments towards changing the pedagogical approach. During the pandemic basically starting in summer 2020 for almost a year, trainers been forced to wrap up massively with skills using digital tools. (cf. Hanapie-Egger, 2020) Before the pandemic there have been multiple reasons why teachers couldn't swop to a virtual online environment teaching. But necessity is the mother of all inventions. With all schools and universities shut, and all students and pupils at home, trainers and teachers had to act. They trained each other defined new standards and created a virtual teaching environment on a trial and error base. Looking at the feedbacks of the students in the first phase, it worked and students adapted faster as expected.

\footnotetext{
${ }^{1}$ John Dewey, 1859-1952, https://beruhmte-zitate.de/zitate/792100-john-dewey-if-we-teach-todays-students-as-wetaught-yesterda/
} 


\section{Analysis of Learnings 2021}

As stated before, after some time being fairly unproductive waiting that the pandemic will disappear soon, all institutions, schools and universities got very creative. Next to self-learning exercises a lot of video's, online streaming, YouTube been tested. Pretty soon each institution tested applications for video conferencing to provide real time online trainings. While trainers and teachers had to be educated and the students have been very open to new teaching formats. Students in Austria and Germany which had 95\% classroom training their entire education time swopped to $100 \%$ virtual teaching within a week.

Supporting the hypotheses, the answers of two main questioners will be considered. The first questionnaire was executed 3 months after the shutdown. Bachelor and Master students been asked with the average age between $20-30$ years. The institute is mainly about technical subjects, digitalization and computerized topics have not been new to them. About 140 students been asked and the return was 90 filled questionnaires. To support hypothesis 1 - 'Students have been prepared before the pandemic' entering the digital century. Some of the tools which been used all of a sudden haven't been new to them and they feel comfortable using them. They evaluated MS teams as an online teaching tool positively as well as the overall experience and efficiency of virtual classrooms. Looking at these tables of figure 5 - hypothesis 1 can be confirmed. Students have been prepared pre-pandemic to use technical tools and are able and willing to use them.
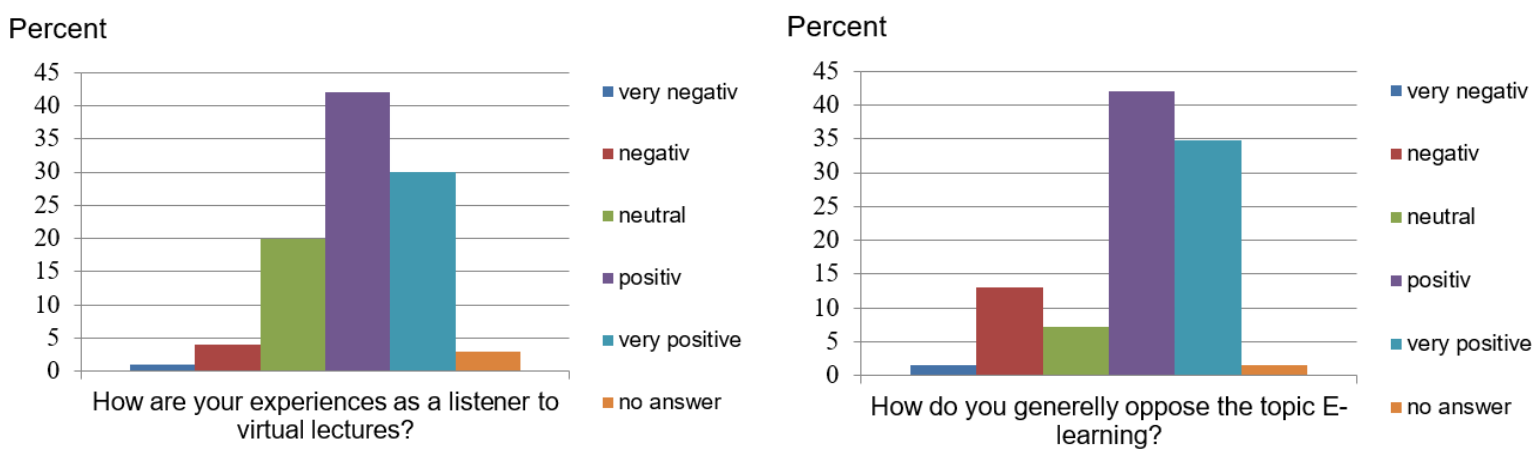

Figure 5: Evaluation of online experience, 2020 created by author

After the second and third wave of the pandemic trainers get more professional as well as students got used to the new learning structures. It started with just trying out a lot of things in autumn 2020 getting much more profound in spring 2021. A new set of questions been asked to pupils and students to check the situation after almost a year of mixed method education. Firstly, thinking they all just want to be back to 'normal' the pandemic time was to long. They got used to new methods and have a very clear opinion about the education of the future. The feedback to the questionnaire in May, 2021 was 34 complete filled sets. If they just had to choose one method, most want to be back in classroom but very clearly stating with new technical tools to be used like iPad's, videos, surveys, additional online parts. Therefore, another question was, about the most preferred mix for the future. Asking if online classes should remain about $70 \%$ agree. 


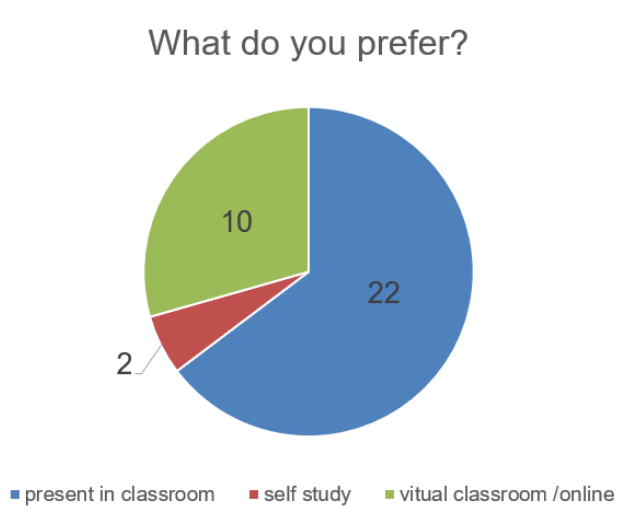

\section{Percent}

Figure 6: Evaluation of preferred teaching, 2021 created by author

Looking at the details of the charts of figure 6 the pre-pandemic situations with hours of passive classroom training should not be repeated past-pandemic. Students clearly state the need of mixed education using various technical tools. Hypothesis 2 and hypothesis 4 can positively be confirmed. To support the second one, students been asked if they do see advantages of the new education methods. They all see advantages of online training and self-study. Remarks a lot of very positive ideas how to continue in the future of learning have been added.
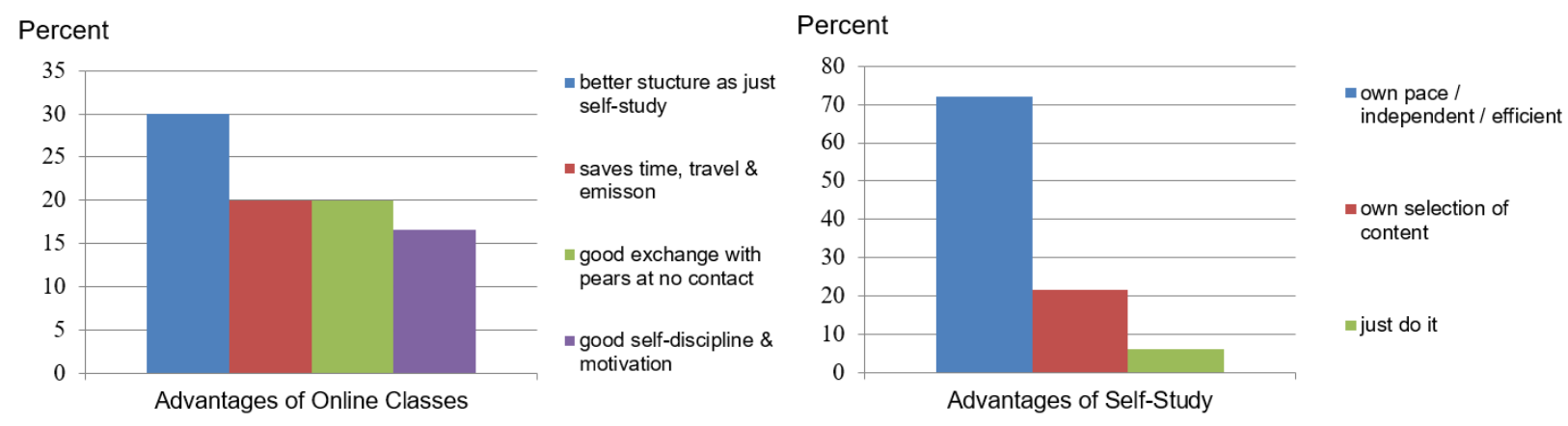

Figure 7: Advantages of new methods, 2021 created by author

Hypothesis 3 has been taken from years of experience working with students in laboratories as well with a lot of practical case studies. Therefore, the method of project-based learning has been executed the last 6 years and will remain one of the key learning methods to justify being present.

Cross-disciplines the method of project-based learning should qualify the students for modern working competences. The basic theories and skills are trained during lectures. The projects selffocus on different engineering skills and supports the students to find their profession based on their interests. The projects are organized similar to the industries, being self-paced by the student groups and only coached by the lectors. 
One case study example at the lecture was the combination of three topics to develop an autonomic self-driving car. Skills in construction, sensors, automation and programing had been required in a project-based team to fulfill all requirements and win a challenge. Developing in a team, learning from each other, finding solutions to various problems set the foundation for very solid knowledge beyond theoretical lectures. The challenge to follow a black line as well as driving without crashing into the ring fence was executed to perfection by all teams not without swearing, disbeliefs and crashes beforehand. All teams celebrated success with their cars but even more, they learned a lot by practical doing things, learning from each other and their own errors. In the end, the feedback was very good and the students confirmed they have gained a lot of technical, programming and personal knowledge. This example of the case study, a self-paced engineering project, is just one of many being practiced, enabling students to use these ideas and methods further. They improved in a try-and-error system in a protected learning space.

This method combines the gain of expert engineering skills as well as soft skills outsides everybody's comfort zone as a qualification for life-long learning.

In summary all hypotheses could be confirmed by working with students for the last 10 years in an engineering environment. The surveys even confirmed some areas specifically due to the pandemic Covid-19. 


\section{Conclusion and Next Steps}

Education 4.0 was a synonym for high end digital education supported by digital technologies and devices. The last years it was very slowly filled with concrete action. The World Economic Forum's New Economy and Society Platform aims in 2020 to provide better education by 2030 and find partners to sponsor this program. They state to enable this reskilling revolution new skills to the workforce has to be delivered as well as a new learning ecosystem and mechanism to teach and learn. The gap between education and jobs been widened even with clear new requirements on skills of the industry. The education system does need a boost and the initiative Education 4.0 did get more attention by a new force, the pandemic in 2020. Standards need to be developed as well as increase technology-enhanced learning experiences. (cf. n.a., 2020, WEF).

This paper examined the challenges for Education 4.0 by the introduction of Industry 4.0 as well as the additional extreme situations related to the pandemic. Overall the pandemic seemed to be a promoter of the changes for digital education and technical education methods and devices. The key research questions investigated in the situations pre- and post-pandemic.

The overall key research questions for this paper are:

'What is the role of online-education past the pandemic?'

'What could be a new setting in education taking the learnings from the pandemic Covid19 to map new requirements from the industry and for future jobs?'

Both questions could be answered in the context of the research and with questionnaires executed in 2020 and 2021. To answer the first question, online Education will remain having a role cross all education situations. Pure classroom training is replaced, now a lot of new mixed structures need to be developed. Specifically, if people come to a classroom there need to be a value provided. Online Formats will be used for theoretical matters as well as for repetitive learning. Students experienced the advantage to learn at their own pace and level of intensively. The experience of this will not disappear even more new education strategies will be developed. Answering question two bases on literature research and the experience of the example of project-based practical teaching. (cf. Boivin, 2021). Education 4.0 need to be developed on the basis of requirements from the Industry related to skills as well as a new strategy for mixed training concepts. For example, faculty have increased their comfort with video conferencing and leaning management systems but the approaches just been tested and improved over time. So, the new strategy needs to include flexibility as well as technology. Educators need to be trained significantly starting tomorrow, in the field of technical devices but even more in mixed education structures.

The momentum of the changes from the pandemic should not be lost and the field of education should not revert back after 2020/2021. 


\section{References:}

- Abdulahagic, T. (2013) Project-based Learning. Vor-, Nachteile und Zusammenhang mit Projektmanagement der Erste Group Bank AG. Magisterarbeit University of Vienna.

- Boivin J., Welby K. (2021) Teaching future educators during a global pandemic. Special Issue: COVID-19: Education Response to a Pandemic Volume 9 Issue 22021.

- Berg, S., Hubertus C.(2020) Die Zukunft des Lernens ist hybird! Learning Experience Report, Whitepaper, Buhr \& Team THIS Shaping Interaction.

- Catalano, H. (2019). Opportunities and Challenges of Education in the Digital Age. No. 14. 2531.

- Deci, E. L. (2012). Promoting Motivation, Health and Excellence (video file). - Retrieved May, $13^{\text {th }} 2021$ 16.20 PM from http://tedxflourcity.com/?q=speaker/2012/ed-deci.

- Duffin, E., Statista, E-learning and digital education Statistics \& Facts, Learning Hours June2020, Responds 1618 students, https://www.statista.com/study/17598/e-learning-anddigital-education-statista-dossier/, 14.05.2021 02:47 PM

- Fadel, C., Bialik, M., Trilling B. (2017) Die vier Dimensionen der Bildung. Was Schülerinnen und Schüler im 21. Jahrhundert lernen müssen. ZLL21Verlag Hamburg.

- Frey, C., Osborne M. (2013) The future of employment: How susceptible are jobs to computerisation? University of Oxford and Oxford Martin School. https://www.oxfordmartin.ox.ac.uk/downloads/academic/The Future of Employment.pdf 20.05.2021 4PM

- Gates B. (2018) These Skills will be in-demand in the job market if the Future. CNBC. https://www.youtube.com/watch?v=NUYmTerOsCo 14.05.2021 3PM

- Guo, Q., Zinn, B., Tenberg, R. (2015) Learning in a Mixed Reality System in the Context of ,Industrie 4.0', JOTED $3^{\text {rd }}$ year, 2015 Nr. 2, ISSN 2198-0306

- Gray, A. (2016) The 10 skills you need to thrive in the forth industrial revolution. https://www.weforum.org/agenda/2016/01/the-10-skills-you-need-to-thrive-in-the-fourthindustrial-revolution/ 16.05.2021 7.15PM

- Hanappi-Egger, E. (2020). What digitalization means for universities. EFMD Business Magazine. Global Focus. Feb. $10^{\text {th }} 2020$.

- Llopis G. (2020). Post Pandemic: How must colleges and universities reinvent themselves? Edit Story, Oct.17h 2020, Forbes https://www.forbes.com/sites/glennllopis/2020/10/17/postpandemic-how-must-colleges-and-universities-reinvent-themselves/ May, $12^{\text {th }} 2021$ 02:20 PM

- Meilleur C. (2018) 4 Challenges for education in the digital revolution era, knowledge-one publication, https://knowledgeone.ca/4-challenges-for-education-in-the-digital-revolution-era/ 12.05.2021 9PM

- Meilleur C. (2018a) Top 10 crucial competencies for 2020, knowledge-one publication, https://knowledgeone.ca/top-10-crucial-competencies-for-2020/ 16.05.2021 3PM

- no author, (2021) Redaktion, Digital Passau, 10.05.2021 https://www.muwnachrichten.de/passau/film-ab-fuer-die-lehrer-von-morgen/ 15.05.2021 4:15 PM

- no author, (2020) World Economic Forum - New Economy and Society platform. https://www.weforum.org/projects/learning-4-0 18.05.2021 9:35 PM 
- no author, (2020a) World Economic Forum - What will the future of jobs be like. https://www.weforum.org/videos/what-will-the-future-of-jobs-be-like 18.05.2021 9:35 PM.

- no author (2017) The future of skills employees in 2030. Nesta, Pearson, Oxford Martin School. https://www.youtube.com/watch?v=M908RNij0n8 13.05.2021 11.20AM

- Schuh, G., Anderl, R., Gausemeier J., Hompel ten, M. and Wahlster, W. (2017), Industrie 4.0 Maturity Index. Managing the Digital, Transformation of Companies (acatech STUDY), Munich: Herbert Utz Verlag, p.53.

- Schwab K., Zahihi S. (2020) The future of Jobs. World Economic Forum Report. http://www3.weforum.org/docs/WEF Future of Jobs 2020.pdf 12.05.2021 2PM

- Trarik, A., (2013) Project-based Learning. Vor-Nachteile und Zusammenhang mit Projektmanagement der Erste Group Bank AG. Magisterarbeit Universität Wien

- Trilling, B., Fadel C. (2009). $21^{\text {st }}$ Century Skills: Learning for life in out times. San Francisco: John Wiley \& Sons Inc.

- Vorst v. d., C. (2020) Challenges Learning in the age of Digitalisation and Industry 4.0, IISES Conference June 2020. 